\title{
Gestión del patrimonio carbonífero en contextos recesivos: del sitio aislado a la cuenca minera. Una reflexión a partir de las experiencias de las cuencas Concepción-Arauco en Chile y Nord-Pas de Calais en Francia
}

Juan Carlos Santa-Cruz. Universidad de Concepción, Concepción, Chile.

RESUMEN | En Chile y Francia, el cierre de yacimientos carboníferos se tradujo en desempleo y declive urbano. Tras más de un siglo de actividad, dejó instalaciones, restos y grandes extensiones de territorio abandonados, degradándose. Las ciudades no se encontraban preparadas para enfrentar sus efectos urbanos, sociales y económicos. Interesa conocer la potencialidad del patrimonio minero y qué obstáculos encuentra su gestión, para colaborar en el mejoramiento del medioambiente habitado. El análisis de la gestión patrimonial, planes de reconversión e iniciativas de intervención, muestra que estando escasamente protegido y articulado, el patrimonio desaparece aceleradamente. En cambio, avanzando desde la noción de sitio aislado hacia el de cuenca carbonífera, resulta más fácil integrar el patrimonio en una estrategia territorial para salir del estancamiento. Dos décadas después, la situación en ambos contextos es disímil. En el caso de Chile, ella revela tanto las deficiencias de los instrumentos de planificación disponibles, como la debilidad de los gobiernos locales.

PALABRAS CLAVE | patrimonio, planificación territorial, desarrollo regional.

ABSTRACT In Chile and France the closure of coal mining resulted in unemployment and urban decline. After more than a century of activity, abandoned facilities, ruins and large tracts of abandoned land, were left to be degraded. The cities were not prepared to face their urban, social and economic effects. It is interesting to know the potential of mining heritage and what obstacles its management faces, in order to assist the improvements of the inhabited environment. The analysis of heritage management, conversion plans, planning strategies and intervention initiatives shows that being sparingly protected and articulated, the heritage disappears rapidly. Instead, moving from the notion of isolated site to that of coal basin, it becomes easier to integrate heritage into a territorial strategy that can break the stagnation. Two decades later the situation in both contexts is highly dissimilar. In Chile, both the shortcomings of the available planning tools and the weakness of local governments are revealed.

KEYWORDS | heritage, territorial planning, regional development. 


\section{Introducción}

Una de las principales características de la minería extractiva es su enorme impacto ambiental, cultural y territorial. Altera radicalmente las relaciones económicas, sociales y laborales de los territorios en que se emplaza, tal como lo hace con la morfología de los asentamientos humanos, la topografía del paisaje y sus equilibrios medioambientales. Es también una actividad de naturaleza transitoria, que tarde o temprano debe acabar, sea porque se agotan los yacimientos, o bien porque su extracción deja de ser lucrativa (López \& Pérez, 2013).

Esta misma transitoriedad podría, teóricamente, incluir a los asentamientos humanos y paisajes culturales desarrollados en torno a la minería, definidos por la Unesco como "lugares que combinan el trabajo de la naturaleza y el ser humano, y que son ilustrativos de la evolución de la sociedad humana y del uso del espacio a lo largo del tiempo, bajo la influencia de limitaciones físicas y/u oportunidades presentadas por el medio natural y de sucesivas fuerzas sociales, económicas y culturales" (Unesco, 2013, párr. 47, p. 14). Sin embargo, los efectos ambientales, urbanos, culturales y sociales de la actividad minera no terminan con su fin. Por el contrario, permanecen en el tiempo, condicionando el futuro de los territorios y de las comunidades que los habitan. Son efectos que, en la fase expansiva, se traducen en cambios demográficos, nuevos paisajes e identidades culturales; y que, tras el cierre de los yacimientos, se expresan en desempleo, declive urbano, degradación espacial e incertidumbre, entre otros (Rodríguez \& Medina, 2011).

Existen numerosos ejemplos de poblados que no sobrevivieron a la actividad productiva que les dio vida; por ejemplo, las oficinas salitreras en el norte de Chile (Garcés, 1999) o los pueblos carboníferos de los montes Apalaches en Estados Unidos (Shifflett, 2000). Pero abundan también las comunidades que, habiéndose asentado por décadas y hasta siglos en torno a explotaciones mineras, se resisten a abandonar sus casas, formas de vida y redes de relaciones sociales. Las comunidades más organizadas luchan para evitar la desintegración de su tejido social y lograr la preservación de los espacios significativos para la memoria colectiva; las menos organizadas sufren la desintegración y pérdida del patrimonio cultural.

En Chile, tras el cierre definitivo de las explotaciones mineras entre 1994 y 2008, localidades como Coronel, Lota, Lebu y Curanilahue no se encontraban preparadas para enfrentar los enormes efectos sociales y económicos que traería consigo el fin de la actividad minera. Sin una política nacional respecto de cómo llevar adelante la desindustrialización, los gobiernos locales hicieron uso de los pocos elementos que tenían a su disposición. Se toparon de golpe con miles de mineros desempleados, familias sin ingresos, una infinidad de problemáticas sociales en aumento y la agudización de otras arrastradas históricamente, junto a enormes instalaciones mineras abandonadas y en estado de degradación.

Ante este escenario, en el último tiempo, en la cuenca carbonífera ConcepciónArauco la preocupación por el patrimonio cultural y su potencial turístico ha ido adquiriendo una particular centralidad (López \& Pérez, 2013). No obstante, dadas las características propias de la actividad carbonífera, para comprender sus valores patrimoniales es imprescindible considerar la red de relaciones socioeconómicas, 
sistemas de transporte y organización del tiempo, sin los cuales las actividades productivas no hubiesen sido posibles. Es decir, se requiere concebir el patrimonio como producto de un entero sistema productivo territorial, que excede el sitio aislado. Un paso en este sentido lo constituye la noción de "parque patrimonial", que a nivel internacional ha evolucionado hacia ejemplos tales como el paisaje industrial de Blaenavon en Gales, declarado Patrimonio de la Humanidad en 2000. O bien, el Área Patrimonial Nacional del Carbón en los montes Apalaches, Estados Unidos, que agrupa sitios patrimoniales de trece condados del Estado de Virginia Occidental (Marshall, Rog, Ogunbyi \& Dubsky, 2012).

Contextos como el francés han avanzado rápido en esta dirección, desde la identificación como Monumento Histórico de las primeras cabrias individuales en los años noventa para evitar su demolición, hasta la declaración de una completa cuenca carbonífera (Nord-Pas de Calais en Francia) como Patrimonio de la Humanidad en 2012. En el caso chileno, en cambio, observando cómo se ha abordado la gestión del patrimonio carbonífero, es posible advertir una visión centrada en la conservación y restauración del elemento individual. Ha costado no solo superar la concepción museística monumental, sino también los límites del sitio o de la comuna específica.

Entendiéndose que cada Estado firmante de la Convención del Patrimonio Mundial de 1972 tiene "la obligación de identificar, proteger, conservar, rehabilitar y transmitir a las generaciones futuras el patrimonio cultural y natural" (Unesco, 2014, p. 34), se suele dejar en manos de la iniciativa estatal dicha responsabilidad. Pero en un marco en el cual no se cuenta con las herramientas adecuadas, los recursos necesarios y la voluntad política para hacerse cargo de su gestión, el patrimonio sufre de abandono y degradación, con el riesgo de desaparecer (Torres, 2013). En este caso, el principal objetivo de la gestión patrimonial debe ser "la protección eficaz de los valores patrimoniales de un bien o un grupo de bienes culturales para las generaciones presentes y futuras y, en un plano más amplio, el suministro de beneficios a la sociedad" (Unesco, 2014, p. 56).

En este contexto, uno de los aspectos críticos dice relación con determinar los valores patrimoniales, para poder definir los límites físicos de las áreas patrimoniales sobre las cuales implementar las eventuales estrategias de gestión. Así, a comienzos de los años 2000 se señalaba la necesidad de desarrollar "estrategias de gestión que definan y monitoreen adecuadamente los límites" de los bienes patrimoniales, identificando zonas de amortiguamiento y áreas de influencia más vastas (Unesco, 2014, p. 16).

En varias comunas de la cuenca Concepción-Arauco, se ha identificado el patrimonio cultural de carácter carbonífero y su potencial turístico como el principal recurso disponible para enfrentar el declive urbano provocado por el cierre de los yacimientos. La experiencia internacional enseńa que, acompańada de una perspectiva de futuro o de salida del estancamiento que sea realista y parezca posible, una estrategia territorial construida sobre los recursos y elementos propios de las comunidades que habitan los territorios puede tener algún grado de éxito (Reicher, 2008; Rink, Haase, Bernt, Arndt \& Ludwig, 2010; Santa Cruz, 2014). Surge entonces la siguiente pregunta: ¿en qué medida la gestión del patrimonio minero constituye 
un recurso susceptible de ser aprovechado para mejorar, tanto las condiciones objetivas del ambiente habitado en contextos recesivos, como la percepción subjetiva de pertenecer a un territorio con una importante historia y una arraigada identidad?

Para responder a la interrogante central es necesario, en primer lugar, hacer una reconstrucción histórica detallada, que sirva de marco de referencia y permita comprender el alcance e importancia territorial de la actividad carbonífera en la Región del Biobío. Solo de esta forma se podrá dimensionar la cuenca carbonífera como sistema productivo territorial y la urgencia que reviste la protección de su patrimonio. En segundo lugar, se requiere una descripción detallada de la situación actual del patrimonio minero en las diferentes comunas involucradas, sobre la base de la información proporcionada por el Consejo de Monumentos Nacionales y las respectivas municipalidades.

En este artículo se plantea un análisis que integre y entrecruce información proveniente de: (i) los planes de reconversión productiva de los territorios involucrados; (ii) los indicadores sociodemográficos de las distintas comunas, publicados por la encuesta de Caracterización Socioeconómica (Casen) y el Observatorio Urbano del Ministerio de Vivienda y Urbanismo (Minvu); (iii) las iniciativas de gestión y tutela del patrimonio industrial local, con énfasis en los instrumentos disponibles y en iniciativas específicas (públicas o comunitarias) de manejo del patrimonio.

El caso chileno se contrastará con la experiencia de la cuenca carbonífera de Nord-Pas de Calais, en Francia, buscando comprender cómo la institucionalidad ha impulsado procesos de reconversión e identificando las trayectorias de gestión patrimonial de ambos casos. El caso de Nord-Pas de Calais, a pesar de las diferencias evidentes que existen entre Chile y Francia, guarda ciertas similitudes con el de la cuenca Concepción-Arauco y sirvió de inspiración durante el proceso de reconversión en Lota y Coronel (De Dinechin, 2001), aun cuando ello no se haya plasmado efectivamente en los planes aplicados.

Desde esta perspectiva, se invita a reflexionar respecto de los límites de las políticas implementadas y de los instrumentos disponibles, pero también respecto de la debilidad de los gobiernos locales y las comunidades para hacer frente a este desafío por sí solos. Con tal fin, se intentan identificar mecanismos capaces de aprovechar la potencialidad del patrimonio carbonífero tanto para la construcción del territorio por parte de las comunidades que lo habitan, como para el mejoramiento efectivo de sus condiciones de vida.

\section{Trayectorias diferentes de un proceso común}

$\mathrm{Al}$ analizar la cuenca carbonífera Concepción-Arauco a la luz de lo ocurrido en Nord-Pas de Calais en Francia, no se olvida en ningún instante que cada contexto es parte integrante de sistemas económicos profundamente diferentes y virtualmente incomparables entre sí. Sin embargo, las historias de las explotaciones carboníferas en diferentes partes del mundo poseen ciertas regularidades, dadas las características intrínsecas de la actividad y los límites impuestos por los modos de producción en cada fase histórica. Ambas regiones fueron testigo de durísimas condiciones de 
trabajo, con jornadas extenuantes, con escasas medidas de seguridad, explosiones de gas grisú y derrumbes que dejaban decenas de muertos. ${ }^{1}$

A comienzos del siglo xIX se había generado una explosiva demanda de carbón para abastecer tanto a las industrias que se multiplicaban (Albrecht, 2012), como a los ferrocarriles que conquistaban nuevos territorios y los buques a vapor que abrían nuevos mercados. La respuesta fue el surgimiento de poblados mineros en zonas tan diversas como Gales en el Reino Unido, la cuenca del Ruhr en Alemania, Silesia en Polonia, Valonia en Bélgica, Asturias en España o Nord-Pas de Calais en Francia en Francia, todos lugares que debieron enfrentar los efectos económicos, sociales y ambientales del cierre de los yacimientos entre los ańos setenta y noventa (Asociación de Regiones Mineras de Europa [Euracom], 2006). Chile también fue objeto de ese proceso.

\section{La cuenca carbonífera de Nord-Pas de Calais en Francia}

Surgida en la segunda mitad del siglo Xviır, la explotación de yacimientos de carbón en Nord-Pas de Calais en Francia se expandió en una zona eminentemente rural gracias al impulso conferido por la revolución industrial. Se dio comienzo así a un nuevo paisaje cultural de carácter industrial, con una proliferación de piques subterráneos salpicados por todo el territorio, inicialmente en las zonas de Anzin y Valenciennes. Gracias a la introducción de la máquina de vapor en 1802, la actividad carbonífera transformó profundamente el territorio de Pas-de-Calais en tan solo cincuenta ańos, creando numerosos barrios, villorrios y obreros en torno a los piques.

La cuenca fue duramente golpeada por la crisis del sector carbonífero en la década de 1960, programándose la reducción de la producción y el cierre de las minas en las décadas de 1970 y 1980. En 1983 se anunció la decisión de detener la extracción de carbón en Francia, comenzando a implementarse el plan de reconversión industrial. Finalmente, el 21 de diciembre de 1990 ocurrió el cierre definitivo del último pique en funciones, en la localidad de Oignies (Dumont \& Debrabant, 2010). Ello puso fin a una actividad que se había extendido por más de dos siglos.

En la década de 1830 se vivió un periodo de expansión especulativa en el cual se descubrieron nuevos yacimientos en Oignies, Douai y Bèthune. En la medida en que se expandía la actividad se profundizaba el problema de la vivienda obrera, lo que llevó al nacimiento de una serie de villes usines por todo el territorio. Hacia mediados del siglo xIx, la maison ouvrier, diseñada por los ingenieros de las propias minas, ya poseía mejores estándares de calidad. Intentando romper con la monotonía, fueron asignándoles un carácter propio a los conjuntos de vivienda de cada compañía (Dumont \& Debrabant, 2010), proceso que fue reflejando algunas de las utopías urbanísticas surgidas en la segunda mitad del siglo XIX, asociadas al paternalismo industrial: "les corons" (1820-1890), las "cités pavillonaires" (1860-1839) y la "ciudad jardín” (1904-1939), tipologías que coexistieron hasta la irrupción del urbanismo

El último gran accidente ocurrido en Francia tuvo lugar en Liévin en 1974, dejando un saldo de 42 muertos. En Chile, el último gran accidente ocurrió en Coronel en 1994, provocando la muerte de 21 mineros en el pique Arenas Blancas. 
moderno en la segunda posguerra (Rolos, 2008). Todo ello fue dando lugar a una particular imagen urbana, que luego dotaría de un carácter singular a toda la región.

Hacia 1900 ya se contaban en 30.000 los mineros que trabajan en los yacimientos de toda la cuenca, infraestructura que se vio en gran parte destruida durante la Primera Guerra Mundial. La reconstrucción de posguerra mejoró los procesos industriales, renovando maquinaria y sistemas ferroviarios. Sin embargo, en la década de 1930 la actividad entró en crisis, produciéndose drásticas reducciones de personal. La Segunda Guerra Mundial implicó la deportación de 18.000 mineros de Nord-Pas de Calais en Francia a la cuenca del Ruhr en Alemania, los que fueron suplidos con mano de obra no calificada compuesta por prisioneros de guerra soviéticos y yugoslavos, además de estudiantes del Servicio de Trabajo Obligatorio. Finalizada la guerra se nacionalizaron los yacimientos, creándose la Charbonnage de France y otros organismos públicos encargados de administrar cada cuenca. Se experimentó un rápido proceso de modernización que dejó en funcionamiento solo los piques más rentables (Dumont \& Debrabant, 2010), a la vez que provocaba enormes impactos ambientales y espaciales, alterando la morfología del paisaje de la zona.

Figura I | Cuenca carbonífera Nord-Pas de Calais en Francia, elementos considerados Patrimonio de la Humanidad por la Unesco

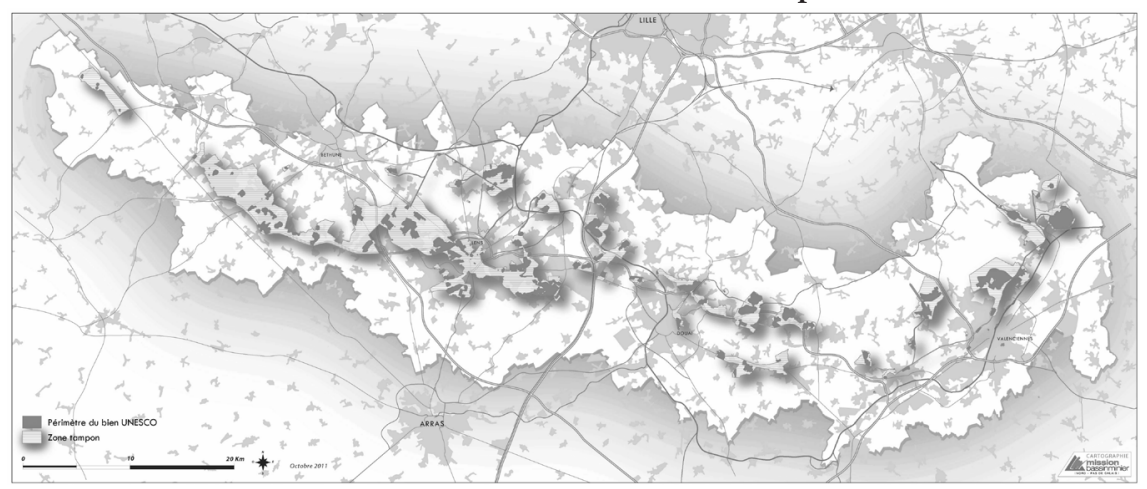

FUENTE MISSION BASSIN MINIER NORD-PAS-DE-CALAIS. HTTP://WWW.ATLAS-PATRIMOINES-BASSINMINIER.ORG/FR/UNESCO-I 7.HTML

\section{Explotación de carbón en el sur del mundo}

Si bien desde tiempos de la colonia se conocía la presencia de mantos carboníferos en el borde costero de Concepción en Chile, la extracción de carbón comenzó luego de la liberalización del puerto de Talcahuano. Desde la década de 1820, marinos británicos comenzaron a extraer carbón superficial para abastecer a sus naves de modo rudimentario (Mazzei de Grazia, 1997). Por otra parte, la expansión de la navegación comercial obligaba a buscar zonas de abastecimiento de combustible para las naves que cruzaban el estrecho de Magallanes. La explotación industrial del carbón comenzó recién en 1841, cuando el estadounidense William Wheelwright dio inicio a la explotación del primer yacimiento de carbón en el sector El Morro 
de Talcahuano (Danus \& Vera, 2010, p. 54), ${ }^{2}$ para satisfacer las necesidades de las naves que recalaban en dicho puerto. A esta primera explotación le siguieron varias otras en distintas localidades vecinas (tabla 2).

Este escenario llevaría a Matías Cousiño a formar la Compañía de Carbón de Lota en 1852, destinada a suplir la necesidad de combustible de sus actividades mineras en el norte del país. Con tal fin instaló en 1854 una fábrica de ladrillos refractarios para uso industrial, y en 1857 una fundición de cobre (Astorquiza \& Galleguillos, 1952). En Coronel, en 1859, Federico Schwager haría lo propio en el fundo Boca Maule, donde construyó en 1867 una fábrica de ladrillos (Aracena, 1884). Años más tarde, en 1892 , adquiriría el yacimiento Puchoco Delano, ${ }^{3}$ dando origen a la Compañía Carbonífera y de Fundición Schwager s.A. En 1885, Ramón Rabal comenzó la explotación de la mina Los Ríos de Curanilahue; en 1902 adquirió las minas Colico, y años más tarde, Las Plegarias (Pérez \& Sanhueza, 2015).

TABLA I | Cronología de algunos de los primeros yacimientos de carbón en el litoral del Biobío

\begin{tabular}{|c|c|c|}
\hline AÑo & YACIMIENTO (PROPIETARIO) & COMUNA \\
\hline 1841 & El Portón (William Wheelwright) & Talcahuano \\
\hline 1843 & Lirquén (Thomas Smith) & Penco \\
\hline 1844 & Tierras Coloradas (John Mackay) & Talcahuano / Penco \\
\hline 1844 & Cerro Corcovado (José Ignacio Palma) & Coronel \\
\hline 1848 & Cerro Verde (Thomas Smith) & Penco \\
\hline 1849 & Puchoco (Jorge Rojas) & Coronel \\
\hline 1850 & La Higuerilla & Tomé \\
\hline 1852 & Lota (Cousiño \& Cía.) & Lota \\
\hline 1856 & Coliumo (John Mackay) & Tomé \\
\hline 1857 & Puchoco (Delano \& Cía.) & Coronel \\
\hline 1859 & Boca Maule (Federico Schwager) & Coronel \\
\hline 1866 & Lebu (Mackay, Urmeneta y Errázuriz) & Lebu \\
\hline 1880 & Buen Retiro (Cousińo \& Cía.) & Coronel \\
\hline $1884 ?$ & Yacimiento de David Fuentes & Talcahuano \\
\hline 1885 & Los Ríos (Ramón Rabal) & Curanilahue \\
\hline 1895 & El Molino (Francisco Chávez) & Tomé \\
\hline 1905 & Compañía Carbonífera Ríos de Chile & Curanilahue \\
\hline 1912 & Dichato (Vicente Palacios) & Tomé \\
\hline
\end{tabular}

2 En el Boletín de la Sociedad Nacional de Minería 119, de 1907, aparece Wheelwright como el primero en explotar carbón de forma industrial. No obstante, Luis Ortega (1988) señala que la primera mina de carbón habría sido la de John Mackay, y la de Wheelright habría comenzado a funcionar al año siguiente.

3 Si bien el apellido Delano ha sido "castellanizado" a Délano, el apellido del empresario minero William Delano Ferguson, nacido en EE.uu., no llevaba tilde. 
En la segunda mitad del siglo XIX, el carbón se volvería fundamental para tres actividades: el comercio marítimo, la gran minería y los ferrocarriles. En torno a estas explotaciones crecieron rápidamente asentamientos de gente en busca de trabajo y mejores condiciones de vida, proveniente de sectores rurales y, en menor medida, de las zonas mineras del norte del país. La población pasó así de un puñado de habitantes a varios miles en pocos ańos. Instalados en un comienzo en barracas y casuchas, en poblados con calles de barro, sus malas condiciones de vida impulsaron a los industriales a proveer de habitaciones (pabellones) de mejor calidad a los mineros y a sus familias. Se quería así reducir la conflictividad laboral, derivada de las paupérrimas condiciones de vida y trabajo. Con ello se dio surgimiento a sectores bien diferenciados en cada una de las localidades.

En Lota los mineros residían en el sector Lota Alto, "un recinto cerrado, controlado y jerarquizado que permitía vigilar los flujos de ingreso y salida del espacio urbano empresarial" (Godoy, 2015, p. 124), en torno a una calle de doce cuadras de largo, con callejones transversales donde se emplazaban los pabellones mineros, compuestos por pequeñas casas de ladrillo, cimiento y techos de teja, con corredores exteriores (Aracena, 1884). En contraste, hasta 1875 Lota Bajo fue un poblado desarrollado fuera del control empresarial y del reconocimiento estatal. Una situación análoga era posible observar en Coronel, donde los asentamientos mineros Puchoco, Maule o Buen Retiro se fueron consolidando independientemente del poblado que surgió en la zona portuaria. En menor medida, este fenómeno se observó en Lebu y Curanilahue. En Lebu la expansión ocurrió desde el fuerte hacia el cerro, separadamente del sector Boca Lebu donde se emplazaba la empresa (Pérez \& Valenzuela, 2010). En Curanilahue, con menor planificación urbana, los sectores diferenciados fueron creciendo orgánicamente siguiendo la topografía del territorio (Pérez \& Sanhueza, 2015). A lo largo del siglo xx, estas ciudades se fueron consolidando, atrayendo otras actividades, equipamientos e infraestructura.

Al norte de la cuenca, la producción de la mina de Lirquén se empleaba para satisfacer las necesidades de la refinería de azúcar CRAV de Penco ${ }^{4}$ y posteriormente de Vidrios Lirquén, terminando sus operaciones en 1958. Aunque se generaron caseríos en torno a las minas y el puerto, no se desarrolló un poblado minero propiamente tal. Desde entonces, la actividad carbonífera se concentró en la parte sur de la cuenca, entre Coronel y Lebu. fue adquirida en 1924 por la Compañía de Refinería de Azúcar de Viña del Mar (CrAv), de 1873, de la cual adoptó el nombre. Véase V. Figueroa (2012). El libro de oro de la historia de Penco. Talcahuano: Trama. 
FIGURA 2 Mapa de yacimientos carboníferos de la cuenca Concepción-Arauco (1841-2008)

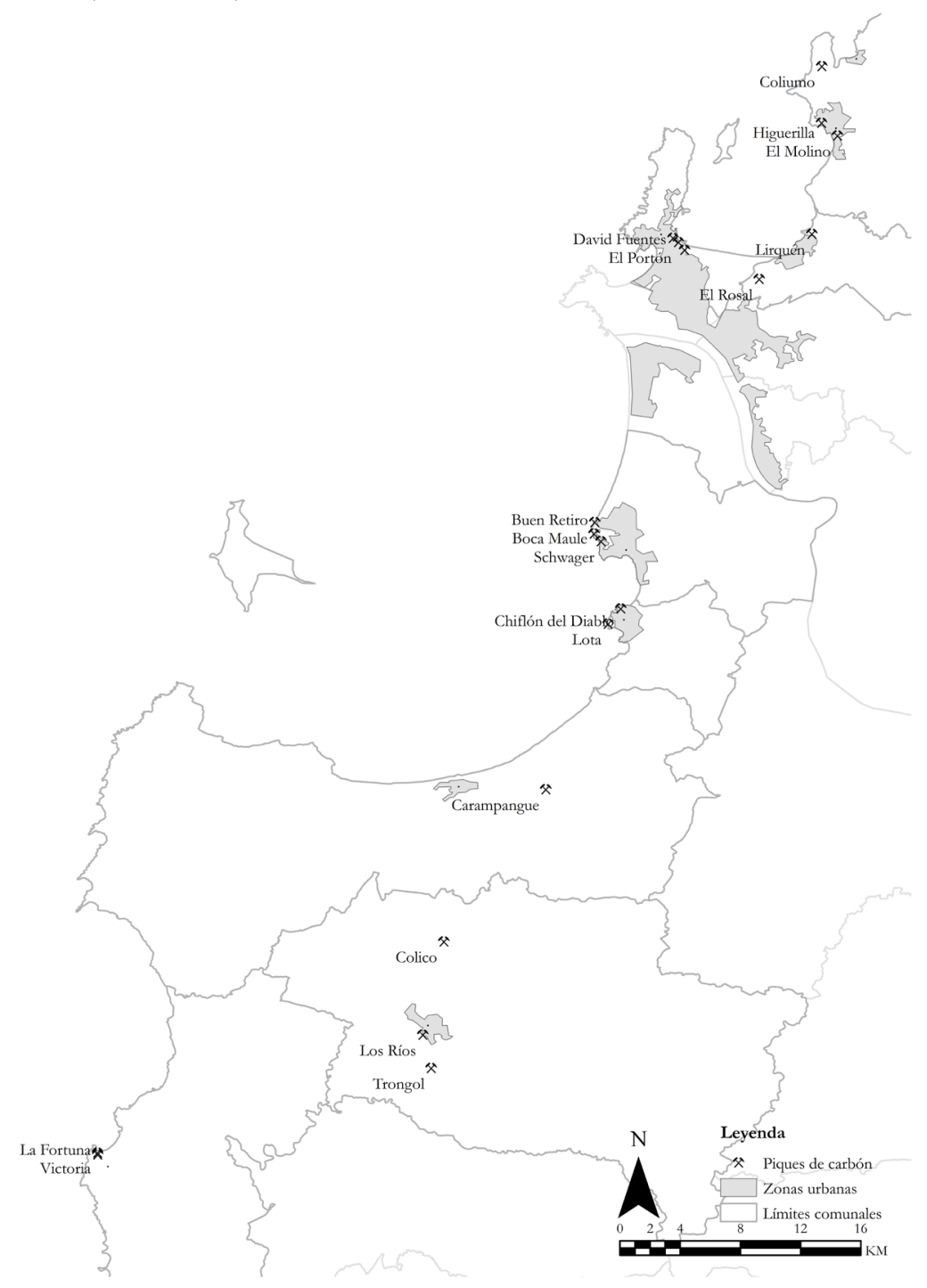

FUENTE ELABORACIÓN PROPIA CON COLABORACIÓN DE LA ARQ. MACARENA SOLAR

En 1964, las minas de Lebu, Carampangue y Curanilahue se fusionaron, teniendo al Estado como accionista mayoritario. Ese mismo año, las compañías fundadas por Schwager y Cousiño también se fusionaron, dando origen a la Carbonífera Lota-Schwager, que en 1970 pasaría a ser mayoritariamente propiedad del Estado. Posteriormente, en 1973, ambas compañías estatales se unieron bajo el nombre de Empresa Nacional del Carbón s.A. (Enacar) (Danus \& Vera, 2010). En aquel entonces, 
en Enacar trabajaban 16.000 personas, número que descendería a 5.900 en 1982. Tras un largo proceso de decadencia, en 1994 se decretó el cierre la mina Schwager, de Coronel, y en 1997 se decidió el cierre definitivo del yacimiento de Lota. Finalmente, en 2006 Enacar cerró la mina Trongol de Curanilahue, y en 2008 finalizó la explotación de la mina La Fortuna, de Lebu, poniendo fin a una historia de casi 170 ańos.

\section{TABla 2 Cronología de la historia del carbón en Nord-Pas de Calais (Francia) y en el litoral de Concepción (Chile)}

\begin{tabular}{|c|c|c|}
\hline \multirow[t]{2}{*}{ CONCEPCIÓN-ARAUCO } & & NORD-PAS DE CALAIS EN FRANCIA \\
\hline & 1757 & Nace la Compagnie des mines d'Anzin \\
\hline \multirow[t]{2}{*}{$\begin{array}{l}\text { Marinos ingleses extraen carbón del borde } \\
\text { costero }\end{array}$} & $1818-20$ & \\
\hline & 1833 & Primera gran revuelta obrera del país \\
\hline $\begin{array}{l}\text { Primeras explotaciones de carbón en } \\
\text { Talcahuano y Lirquén }\end{array}$ & $1841-43$ & Se descubren yacimientos en Oignies \\
\hline Cousiño crea la Compañía de Lota & 1852 & Nace la Compagnie des mines de Lens \\
\hline Lota, primera revuelta obrera del país & 1854 & \\
\hline Se crea la Cía. de Carbón Puchoco, Coronel & $1859-61$ & Surge la villa minera más antigua aún existente \\
\hline \multirow[t]{2}{*}{ Lota y Coronel reciben el título de ciudad } & 1875 & Lens supera los 9.000 habitantes \\
\hline & 1884 & Gran huelga minera \\
\hline \multirow[t]{2}{*}{$\begin{array}{l}\text { Inundación pique minero en Maule, } \\
\text { Coronel }\end{array}$} & 1897 & \\
\hline & 1906 & $\begin{array}{l}\text { Catástrofe de las minas de Courrières } \\
\text { (1.099 muertos) }\end{array}$ \\
\hline $\begin{array}{l}\text { Apertura del canal de Panamá impacta en la } \\
\text { actividad carbonífera chilena }\end{array}$ & 1914-18 & $\begin{array}{l}\text { Primera Guerra Mundial, destrucción de } 103 \\
\text { piques de } 150 \text { existentes }\end{array}$ \\
\hline \multirow[t]{3}{*}{ Gran Huelga Larga, de 80 días } & 1920 & Reconstrucción de las minas \\
\hline & 1930 & Producción récord de 35 millones de ton. \\
\hline & 1946 & Nacionalización de las minas de carbón \\
\hline Producción récord de 3,5 millones de ton. & 1955 & \\
\hline \multirow[t]{2}{*}{ Gran Huelga, suspendida por terremoto } & 1960 & Plan Jeanneney, recesión del sector minero \\
\hline & 1963 & Huelga general \\
\hline Nacionalización de las minas de carbón & $1968-70$ & Se programa el fin de las minas para 1983 \\
\hline \multirow[t]{3}{*}{ Cierre del Chiflón del Diablo } & 1976 & \\
\hline & 1990 & Cierre del último pique en funciones (Oignies) \\
\hline & 1992 & $\begin{array}{l}\text { Se declaran Monumento Nacional cinco } \\
\text { piques }\end{array}$ \\
\hline Cierre de las minas de Coronel y Lota & $1994-97$ & \\
\hline Cierre de las minas de Lebu y Curanilahue & 2006-08 & \\
\hline \multirow[t]{2}{*}{$\begin{array}{l}\text { Se declaran Monumento Nacional (MN) } \\
\text { los primeros tres sitios mineros, en Lota y } \\
\text { Coronel }\end{array}$} & 2008-10 & $\begin{array}{l}\text { Se declaran Monumento Nacional } 41 \text { sitios } \\
\text { mineros }\end{array}$ \\
\hline & 2012 & $\begin{array}{l}\text { La cuenca minera Nord-Pas de Calais en Fran- } \\
\text { cia es declarada Patrimonio de la Humanidad } \\
\text { por la Unesco }\end{array}$ \\
\hline 14 sitios mineros son declarados MN en Lota & 2014 & \\
\hline
\end{tabular}

FUENTE ELABORACIÓN PROPIA CON INFORMACIÓN DE CONSEJO DE MONUMENTOS NACIONALES (CMN) (WWW.CMN.CL); DANÚS Y VERA (20IO); DUMONT Y DEBRABANT (20IO); MAZZEI (I997); PÉREZ Y SANHUEZA (2OI 5); PÉREZ Y VALENZUELA (2OIO); Y LOS SITIOS MEMORIA CHILENA (WWW.MEMORIACHILENA.CL) Y BASSIN MINIER NORD-PAS DE CALAIS EN FRANCIA (WWW. ATLAS-PATRIMOINES-BASSIN-MINIER.ORG) 


\section{Del cierre a la reconversión}

Una diferencia sustancial entre ambas realidades, la chilena y la francesa, radica en el modo a través de cual se hicieron cargo de la catástrofe laboral y social que provocó el fin de la actividad minera. Teóricamente, en ambos casos (con décadas de diferencia) se habría recurrido al mismo tipo de respuesta: la reconversión. Pero con diferencias tales que los convierten en dos modelos completamente diferentes.

Francia apostó por la reconversión productiva como parte de una planificación mayor, que incluía subsidios, jubilaciones anticipadas, programas sociales y la instalación de nuevas fábricas.

El plan de reconversión productiva comenzó a ser preparado por el Estado a partir de 1967, con el objetivo de lograr la reindustrialización de la zona por la vía de atraer industrias a los lugares en los cuales se iban cerrando los yacimientos. En Douai se instaló una fábrica de la Renault en 1972 y una planta de la Imprenta Nacional en 1974 (Dumont \& Debrabant, 2010). Uno de los aspectos positivos que tuvo la reconversión es que se hizo de manera progresiva, comenzando cuando varios yacimientos estaban aún en funcionamiento, y disminuyendo con ello el impacto social del fin de las actividades. No obstante, pese a los esfuerzos por diversificar la industria, no se lograban los resultados esperados, manteniéndose altas tasas de desempleo en ciudades como Lens o Valenciennes (Euracom, 2006). En vista de que no se despertaban las capacidades intrínsecas del territorio para generar un desarrollo endógeno y se seguían arrastrando altas tasas de desocupación, hacia el año 2000 la cuenca carbonífera fue incluida como zona prioritaria de la Unión Europea, ${ }^{5}$ siendo objeto de iniciativas como el programa Urban II (Comisión Europea, 2003). Se asignaron recursos y se adoptaron nuevas medidas para reactivar la zona, pero esta vez promoviendo la economía del conocimiento, el turismo y el incremento de la competitividad urbana, especialmente apelando a sus factores únicos e irreproducibles.

En este contexto, varios lugares de la cuenca vieron nacer iniciativas comunitarias surgidas de la preocupación por la recualificación ambiental (por ejemplo, Loos-en-Gohelle), las cuales se sustentaban en el profundo carácter identitario de la región, en el cual el patrimonio minero desempeńaba un rol central. Entonces, la historia de la industria del carbón, la identidad minera local y el patrimonio asociado emergieron como algunos de los principales recursos a los cuales echar mano, impulsando a los gobiernos locales y regionales a idear mecanismos que asegurasen la salvaguardia del patrimonio y a partir de los cuales se pudiesen construir estrategias de desarrollo a mediano plazo.

Un aspecto relevante es que, a mediados de la década de 1990, la experiencia de reconversión productiva de la antigua zona carbonífera del noreste francés fue vista - a nivel teórico - como fuente de inspiración para los planes de reconversión que se comenzaban a aplicar en las comunas de Lota y Coronel. Dada la similitud de los procesos en curso y la amplitud de los territorios afectados, se propuso una salida similar: la reconversión productiva sobre la base de subsidios y otros incentivos

Las zonas prioritarias eran aquellas en las cuales el PIB per cápita no alcanzaba al $75 \%$ de la media europea. 
para la instalación de empresas (Ministerio de Hacienda, 2004). El caso chileno, sin embargo, no incluyó la gradualidad de las medidas de mitigación adoptadas en Francia y en la práctica se limitó a paliar la emergencia inmediata. Tal como señalaba el objetivo del Programa de Reconversión Laboral y Productiva de la Zona del Carbón en 1997: "Como respuesta a los trabajadores afectados por el cierre de la mina de carbón de Enacar en Lota”, se buscó mantener los ingresos por medio de la jubilación anticipada, la capacitación y la reinserción laboral. Pero se careció de una estrategia de desarrollo coherente asociada al cierre de los yacimientos y no se consideró la necesidad de descontaminar el área. De hecho, este programa surgió tres años después del cierre de las minas de Coronel, y no se previó el cierre de los yacimientos de Lebu y Curanilahue.

Paralelamente, en 1997 se impulsó el Plan de Desarrollo Integral en Lota, de capitales públicos y privados, que incluía un programa de reordenamiento urbano y uno de inversiones públicas, el cual, sin haber sido evaluado en su globalidad, solo fue ejecutado parcialmente (Pérez, Muñoz \& Sanhueza, 2004). Con excepción de Coronel, el resto de las comunas de la cuenca no fue objeto de ningún tipo de programa o iniciativa de desarrollo extraordinaria, fuera del Plan de Desarrollo Comunal, que regularmente prevé la legislación chilena.

Coherentemente con su modelo de desarrollo, la instalación de nuevas empresas se dejó en manos de la libre iniciativa individual. Se limitó a invitar al sector privado a invertir en la zona, utilizando los escasos recursos asignados en implementar el Programa de Reconversión Laboral del Carbón (1992 y 1995), con el objetivo de favorecer la reinserción laboral de los mineros que iban quedando desempleados. Tales recursos consistían en un subsidio equivalente a doce ingresos mínimos mensuales (IMM) ${ }^{6}$ por trabajador, que debían ser usados en capacitación, adquisición de herramientas de trabajo, subsidios de manutención (1 IMM), subsidios de traslado y otros beneficios menores. En total, menos de USD 2.000 per cápita. Sin embargo, se trató de una iniciativa parcial y coyuntural, que no consideraba la complejidad de los factores territoriales y culturales en juego, ni les asignaba valor a la historia y patrimonio minero. La capacitación de la mano de obra local tampoco estuvo asociada a la instalación de nuevas actividades productivas; no hubo estudios de empleabilidad ni planes de empleo. Se llevaron a cabo cursos -a menudo inútiles- de peluquería, panadería o mueblería, que solo servían para tener ocupada a la población.

\section{El patrimonio carbonífero}

El interés por el patrimonio industrial y carbonífero fue incorporado oficialmente en Francia en las políticas culturales recién en los años ochenta, cuando, junto con el cierre de yacimientos, comenzó a realizarse un profundo trabajo de catastro y registro de bienes y sitios industriales y mineros de importancia histórica y cultural (Smith, 2012). En Chile, por su parte, este interés empezó a adquirir visibilidad recién en los noventa, primero en las salitreras del norte del país y más tarde en la cuenca del carbón. 
En términos patrimoniales, la cuenca carbonífera de Nord-Pas de Calais en Francia posee ciertas características que la acercan al caso chileno. En primer lugar, no se trata de una pieza aislada, un sitio o localidad específicos, sino de paisajes culturales enteros, que constituyen un testimonio histórico de procesos y modos de producción ligados a la industria del carbón. En Nord-Pas de Calais en Francia, al igual que en la zona carbonífera chilena, se evidencia la dimensión territorial de procesos culturales que consideran una suma de piezas, sitios, localidades y paisajes culturales, articulados en un único sistema territorial. Además, en ambos casos el reconocimiento patrimonial de los piques mineros es relativamente reciente. Si bien en 1992 fueron declarados Monument Historique los piques 9-9 bis de Oignies, 3-3 bis de Liévin y 2 de Marle, la mayor parte recibió la declaratoria entre 2008 y 2012. En Chile, en tanto, recién en 2008 un pique y su cabria, Arenas Blancas, en Coronel, fueron declarados Monumento Nacional; y al año siguiente, el Chiflón del Diablo, en Lota.

Actualmente el área patrimonial de la cuenca carbonífera Nord-Pas de Calais en Francia abarca $120 \mathrm{~km}$ de largo, en una cuenca de $188 \mathrm{~km}^{2}$, con 353 elementos repartidos en 109 sitios diferentes: piques mineros, cabrias, villas obreras, maquinarias, depósitos, cúmulos de escoria, además de edificios de uso civil, comunitario y religioso, distribuidos en cuatro departamentos (Béthune, Lens, Douie y Valenciennes), donde viven 1.240 .000 personas. Reconociendo el valor universal excepcional de sus paisajes culturales, la cuenca fue declarada Patrimonio Cultural de la Humanidad por la Unesco en 2012 (Mission Bassin Minier, 2012). La cuenca Concepción-Arauco, por su parte, se extiende por poco más de $140 \mathrm{~km}$ en línea recta desde Dichato por el norte a Lebu por el sur, atravesando ocho comunas (Tomé, Penco, Talcahuano, Coronel, Lota, Arauco, Curanilahue y Lebu), que cubren una superficie de $3.114 \mathrm{~km}^{2}$ aproximadamente. Cuenta con 34 elementos con algún tipo de reconocimiento patrimonial: 21 Monumentos Nacionales (MN), 3 Zonas Típicas ( $\mathrm{ZT}$ ) y 10 Inmuebles de Conservación Histórica (ICH), concentrados preferentemente en Lota y Coronel (tabla 3).

A diferencia de lo que ocurre en Francia, en Chile hay una ciudad mayormente asociada a la actividad carbonífera (Lota), siendo la que concentra casi la totalidad del patrimonio industrial declarado Monumento Nacional en la Región del Biobío. Es la ciudad donde más se ha investigado el pasado minero y donde se han llevado a cabo más iniciativas de recuperación o puesta en valor patrimonial, seguida de Coronel (tabla 3). 
TABLA 3 Patrimonio minero según grado de tutela, cuenca ConcepciónArauco, 2016

\begin{tabular}{|c|c|c|c|}
\hline COMUNA & SITIO & TUTELA & TIPOLOGÍA \\
\hline Coronel & $\begin{array}{l}\text { Cabria Pique Arenas Blancas } \\
\text { Administración Mina Maule } \\
\text { Club Maule } \\
\text { Pique Buen Retiro } \\
\text { Colectivos obreros Chollín } \\
\text { Chiflón 4, playa Maule } \\
\text { Pique Santa María } \\
\text { Chiflones de Puchoco } \\
\text { Iglesia Schwager } \\
\text { Estación Escuadrón } \\
\text { Barrio Maule } \\
\text { Ex Mina Schwager }\end{array}$ & $\begin{array}{l}\text { Monumento Nacional } \\
\text { Municipal - ICH } \\
\text { Municipal - ICH } \\
\text { Municipal - ICH } \\
\text { Municipal - ICH } \\
\text { Municipal - ICH } \\
\text { Municipal - ICH } \\
\text { Municipal - ICH } \\
\text { Municipal - ICH } \\
\text { Municipal - ICH } \\
\text { Zona Típica } \\
\text { Zona Típica }\end{array}$ & $\begin{array}{l}\text { Productivo } \\
\text { Administrativo } \\
\text { Comunitario } \\
\text { Productivo } \\
\text { Habitacional } \\
\text { Productivo } \\
\text { Productivo } \\
\text { Productivo } \\
\text { Religioso } \\
\text { Ferroviario } \\
\text { Urbano } \\
\text { Urbano }\end{array}$ \\
\hline Lebu & $\begin{array}{l}\text { Lavadero de carbón Boca Lebu } \\
\text { Casa de Maximiliano Errázuriz }\end{array}$ & $\begin{array}{l}\text { Municipal - ICH } \\
\text { Municipal - ICH }\end{array}$ & $\begin{array}{l}\text { Productivo } \\
\text { Habitacional }\end{array}$ \\
\hline Lota & $\begin{array}{l}\text { Central Chivilingo } \\
\text { Chiflón del Diablo } \\
\text { Teatro de los mineros } \\
\text { Pabellón } 83 \\
\text { Torre Centenario } \\
\text { Gota de Leche } \\
\text { Desayuno Escolar } \\
\text { Lota alto } \\
\text { Pique Alberto y su cabria } \\
\text { Pique Carlos } 1 \text { y su cabria } \\
\text { Pique Carlos } 2 \text { y su cabria termoeléctrica } \\
\text { Galpones planta industrial } \\
\text { Planta lavado carbón } \\
\text { Silo planta de lavado } \\
\text { Silo planta transportadora } \\
\text { Tornamesa } \\
\text { Ruinas cinta transportadora } \\
\text { Edificio búnker } \\
\text { Muelle } \\
\text { Tortas de escoria }\end{array}$ & $\begin{array}{l}\text { Monumento Nacional } \\
\text { Monumento Nacional } \\
\text { Monumento Nacional } \\
\text { Monumento Nacional } \\
\text { Monumento Nacional } \\
\text { Monumento Nacional } \\
\text { Monumento Nacional } \\
\text { Zona Típica } \\
\text { Monumento Nacional } \\
\text { Monumento Nacional } \\
\text { Monumento Nacional } \\
\text { Monumento Nacional } \\
\text { Monumento Nacional } \\
\text { Monumento Nacional } \\
\text { Monumento Nacional } \\
\text { Monumento Nacional } \\
\text { Monumento Nacional } \\
\text { Monumento Nacional } \\
\text { Monumento Nacional } \\
\text { Monumento Nacional } \\
\text { Monumento Nacional }\end{array}$ & $\begin{array}{l}\text { Energético } \\
\text { Productivo } \\
\text { Equipamiento cultural } \\
\text { Habitacional } \\
\text { Productivo } \\
\text { Comunitario } \\
\text { Comunitario } \\
\text { Urbano } \\
\text { Productivo } \\
\text { Productivo } \\
\text { Productivo } \\
\text { Energético } \\
\text { Productivo } \\
\text { Productivo } \\
\text { Productivo } \\
\text { Productivo } \\
\text { Productivo } \\
\text { Productivo } \\
\text { Productivo } \\
\text { Productivo } \\
\text { Paisajístico }\end{array}$ \\
\hline Concepción & Puente Ferroviario Biobío & Municipal - ICH & Ferroviario \\
\hline & \multicolumn{3}{|l|}{ INMUEBLE DE CONSERVACIÓN HISTÓRICA. } \\
\hline Ft & DOS & O DE $N$ & CIONALES (CMN) \\
\hline
\end{tabular}

Lota es, además, la única comuna que articula de cierta forma su patrimonio carbonífero como parte de un circuito turístico que incluye: (i) el museo de sitio Chiflón del Diablo ( $\mathrm{MN})$, pique submarino con una pequeña recreación escenográfica de pabellones mineros en la superficie; (ii) un pequeño museo de la familia Cousiño, propietaria de la mina; (iii) el Parque Lota (MN), que constituía el jardín de la mansión de los Cousińo; y (iv) el barrio Lota Alto, en el cual desde 1997 se han restaurado numerosos pabellones obreros, uno de los cuales fue transformado en centro cultural: el Pabellón 83 (MN). El resto de los monumentos nacionales de 
carácter industrial de Lota, el muelle y los restos ubicados en el sector Chambeque, los piques Alberto, Carlos 1, Carlos 2 y sus respectivas cabrias, permanecen abandonados, degradándose, algunos en pésimo estado de conservación.

Luego del cierre de las minas de Lota, el Estado traspasó a Fundación Chile el Chiflón del Diablo y el Parque Lota para que desarrollase un circuito turístico, en el marco del Plan de Desarrollo Integral de Lota. En 1998 la Municipalidad traspasó la Central Hidroeléctrica Chivilingo, para que se sumara a la iniciativa. Se configuraría así el circuito turístico industrial "Lota Sorprendente", que más tarde incluiría el Museo Histórico de Lota, emplazado en la entrada del parque, y la reproducción del pueblito minero realizada para la película Subterra (Ferrari, Bulo \& Pantoja, 2003). La gestión de tal circuito fue asumida por la Corporación Baldomero Lillo en 2012, a excepción de la Central Chivilingo, que continúa bajo la tutela de Fundación Chile.

En 2002, Enacar, la Secretaría Regional Ministerial (Seremi) de Vivienda, el Gobierno Regional, el Fondo de Solidaridad e Inversión Social (Fosis), el Programa Integral para la Superación de la Pobreza Urbana y la Municipalidad de Lota suscribieron un compromiso de acciones conjuntas para restaurar y recuperar el Pabellón 83 y convertirlo en centro cultural (Ríos, 2011). Más tarde, en 2009, la Municipalidad encargó la restauración del muelle Ex Enacar, dado el valor histórico y patrimonial del sector y su avanzado estado de deterioro, la cual, sin embargo, no pasó la etapa de diseño. Conjuntamente, la Seremi de Vivienda del Biobío formuló en 2010 el Plan de Regeneración Urbana de Lota (por un monto estimado de 12 millones de dólares), que incluía: (i) la revitalización del muelle Enacar (MN) y la construcción de un parque costero; (ii) la restauración del teatro de los mineros (MN); (iii) un paseo y parque en el sector Fundición, donde se emplazan los restos de la Torre Centenario (MN); (iv) un museo del carbón; y (v) la restauración de pabellones (Minvu, 2010). Cada uno de los proyectos contemplaba fuentes de financiamiento diferenciadas, lo que explica que algunos hayan avanzado - como la restauración de pabellones_-, mientras otros no prosperaran.

En el caso del Muelle Enacar de Lota, recién en 2016 se acordó una alianza entre la Corporación de Fomento de la Producción (Corfo) y la Dirección de Obras Portuarias (DOP) del Ministerio de Obras Públicas (MOP), para concretar la rehabilitación del muelle y así potenciar el turismo en el borde costero de Lota (DOp, 2016). Paralelamente, en el mismo periodo algunos inmuebles y ruinas fueron declarados Monumento Nacional para asegurar su conservación, dado su creciente deterioro: el Teatro de los Mineros y el Pabellón 83 en 2009, la Torre Centenario en 2010 y las edificaciones Gota de Leche y Desayuno Escolar en 2012. ${ }^{7}$ Más tarde, en 2014 ocurriría lo propio con el muelle y varios elementos emplazados en el sector Chambeque.

\footnotetext{
"La Gota de Leche, fue el nombre dado a las instituciones creadas para remediar los problemas de desnutrición y alta mortalidad infantil, las cuales comienzan a surgir a finales del siglo xIx en Europa para luego ser replicadas en nuestro país. El inmueble se ubica en el sector de Lota Alto y corresponde a una edificación construida en el ańo 1928 como un anexo al recinto Hospitalario (...). El edificio Desayuno Escolar fue levantado para atender y entregar una mejor alimentación a los niños y niñas en edad escolar de Lota”. Consejo de Monumentos Nacionales de Chile (CMN), Decreto No250 (2012). En http://test-monumentos.tifon.cl/monumentos/monumentoshistoricos/gota-leche
} 
En Coronel, este tipo de iniciativas tardarían años en aparecer. Recién en 2006 la Municipalidad inauguró el Museo Histórico Minero Puchoco Schwager; en 2008, la cabria del pique Arenas Blancas fue declarada Monumento Nacional y el sector Puchoco-Schwager, Zona Típica, al igual que el sector Maule Schwager en 2012. En el resto de las comunas de la cuenca, las huellas materiales de este pasado van desapareciendo aceleradamente. De las explotaciones de Dichato y Coliumo no quedan rastros, como tampoco hay ninguna clase de marca o señal que recuerde la presencia de un pasado carbonífero en Talcahuano. En Concepción, de las bodegas del ferrocarril del carbón y de la antigua estación Chepe no queda rastro alguno, sobreviviendo la ferrovía actualmente en uso. En Lirquén, para permitir la ampliación del puerto fue destruido el cúmulo de escoria que se alzaba en el puerto (la tosca), que hasta fines del siglo xx era el principal elemento que configuraba el paisaje del borde costero. Queda únicamente el ingreso a un pique minero escondido en una bodega, como el último testigo de la actividad carbonífera. Hay cada vez menos personas ligadas a la minería. Y sin referencias físicas que visibilicen la historia, la memoria de las comunidades que ahí existieron se ha ido perdiendo irremediablemente.

En Curanilahue y en Lebu quedan cada vez menos restos materiales del pasado carbonífero. Subsisten, sin embargo, una identidad y una memoria asociadas a la actividad que dio vida a ambas ciudades, principalmente porque el cierre de dichos yacimientos ocurrió recientemente. En el caso de Lebu, la identidad minera se vio plasmada en la construcción del Parque del Carbón en el lugar donde funcionaba la antigua planta de lavado de carbón, de la cual sobrevive solo un fragmento, mientras que en la antigua casa de administración de la mina funciona un museo minero y se hacen visitas al chiflón Fortuna. En Curanilahue, donde a pesar de que las minas están actualmente abandonadas, en 2009 trabajadores del Sindicato de Obreros Colico Trongol crearon un museo minero en la sede sindical, el primer museo de la ciudad. En 2016 se gestó la Mesa Patrimonial del Carbón de Curanilahue, liderada por el Servicio Nacional de Turismo (Sernatur), con el objetivo de lograr una coordinación entre actores públicos y privados a fin de valorizar el patrimonio histórico, cultural y natural de la comuna. Este escenario muestra, por un lado, lo inadecuado de la institucionalidad vigente para tutelar el patrimonio minero industrial; y por otro, la ineficacia de las políticas aplicadas a nivel central, regional o municipal, para salvaguardarlo.

Pero, ¿̇se puede aprender de la experiencia de la cuenca Nord-Pas de Calais en Francia para elaborar una estrategia destinada a preservar y valorizar el patrimonio carbonífero? Una estrategia capaz no solo de proteger los restos existentes, sino también de visibilizar y poner en valor la historia y las identidades locales, integrando los valores sociales y culturales de la actividad minera de las distintas localidades, concibiéndolas como un todo y no un listado de sitios y piezas individuales. Una estrategia que ponga al centro el patrimonio intangible, es decir, los aspectos simbólicos e identitarios, los saberes, representaciones y expresiones culturales, que son aquellos que — en último término- dotan de sentido a la protección y conservación de los inmuebles.

Tanto en Francia como en Chile, tras el cierre definitivo de los yacimientos, comenzaron a deteriorarse y destruirse buena parte de las instalaciones mineras. 
En Nord-Pas de Calais en Francia, para evitar la desaparición de estos elementos, a partir de 1992 algunas cabrias y piques fueron declarados Monumento Nacional, al igual que la Maison Syndicale des Mineurs en Lens en 1996, gracias a la acción de actores de la comunidad y el sector público (municipal), que se organizaron para evitar su demolición. En Chile, si bien la Central Hidroeléctrica Chivilingo había sido declarada Monumento Nacional en 1990, el reconocimiento patrimonial de las instalaciones, equipamiento comunitario y viviendas mineras debería esperar más de una década desde el cierre de las minas de Coronel y Lota.

A pesar de las diferencias entre los casos francés y chileno, hasta este momento ambos presentan ciertas similitudes en el modo de enfrentarse al patrimonio minero. La mayor parte de este se encuentra desprotegido, degradándose; algunos inmuebles significativos se hallan en peligro y las villas y pabellones aún son ocupados por las familias de los antiguos mineros. En torno al año 2000, las trayectorias de ambos casos se bifurcan. En el caso francés, la conciencia respecto de la necesidad de preservar y poner en valor el patrimonio minero se haya consolidada. En el marco de la planificación quinquenal 2000-2006, por acuerdo entre el Estado y la Región, se creó la Mission Bassin Minier Nord-Pas de Calais en Francia, con el objetivo de apoyar la implementación de un programa integral de renovación urbana en la antigua zona minera. En 2003, las entidades Mission Bassin Minier y Chaîne des Terrils prepararon un dossier para candidatear toda la cuenca minera como Patrimonio de la Humanidad de la Unesco, lográndolo nueve años más tarde.

En Chile, en cambio, la preservación del patrimonio y la valorización de la historia de las comunidades han debido enfrentar una pluralidad de dificultades financieras, materiales y administrativas. Entre ellas, el tratamiento fragmentado que se hace del patrimonio que no permite dar con una visión de conjunto que exceda la suma de las partes, y que se tradujo en una falta de coordinación entre los distintos entes, municipios, organismos y organizaciones preocupadas por la preservación y valorización del patrimonio carbonífero.

Conscientes de esta dificultad, en los últimos años se aprecian importantes esfuerzos desde las organizaciones comunitarias y la academia por abordar el patrimonio carbonífero de modo más integral. Se ha avanzado, por ejemplo, en el diseño de una ruta del carbón de Lebu a Coronel. Este esfuerzo, sin embargo, se topa con los límites permitidos por una institucionalidad insuficiente y poco actualizada, que se traducen en que cada pieza patrimonial es manejada como un elemento en sí, que recibe un tratamiento particularizado, salvo excepciones, como los pocos lugares declarados Zona Típica.

Uno de los aspectos que resultaron críticos en los planes de reconversión de ambas cuencas, la chilena y la francesa, dice relación con la gestión de los enormes recintos mineros abandonados. En el caso francés, a partir del ańo 2000, la Mission Bassin Minier Nord-Pas de Calais en Francia comenzó a hacerse cargo de buena parte de ellos, incluyéndolos en el área que sería candidateada como Patrimonio de la Humanidad. Para ello se implementaron instalaciones con oficinas, sedes de entidades, museos, organizaciones y salas de espectáculos como Le Métaphone de Oignies, entre otras actividades. Con ello, y gracias al trabajo de descontaminación del territorio, los yacimientos y cerros de escoria se transformaron en grandes parques donde realizar excursiones. 
FIGURA 3 | Mapa de sectores mineros en Lota y Coronel

LOTA

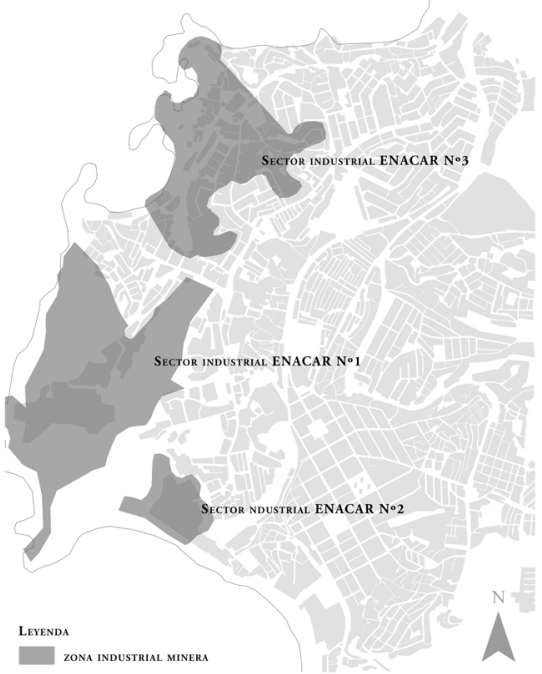

CORONEL

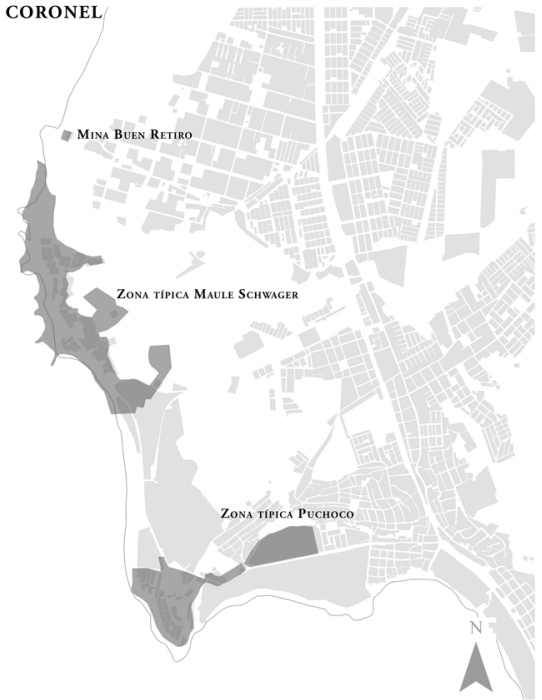

FUENTE ELABORACIÓN PROPIA CON COLABORACIÓN DE LA ARQ. MACARENA SOLAR

En el caso chileno, los planes de reconversión no consideraban el aprovechamiento o reutilización de los inmensos terrenos que ocupaban las instalaciones industriales (figura 3). En Lota, sin un plan de gestión de los recintos 1 y 2 de Enacar, que concentran la gran mayoría de los Monumentos Nacionales, sus instalaciones se deterioraron rápidamente, derrumbándose la cabria del pique Alberto a comienzos de 2017. En Coronel, por su parte, los recintos mineros consideraban las actuales Zonas Típicas de Maule y Puchoco, lo cual tampoco asegura la supervivencia de las construcciones patrimoniales, altamente deterioradas.

\section{Una tarea pendiente: ¿cómo abordar la gestión del patrimonio minero en un contexto socioeconómicamente recesivo?}

El fracaso de la reconversión se expresa en que a dos décadas del cierre de las minas de Lota y Coronel, los indicadores socioeconómicos de la cuenca del carbón son profundamente deficitarios. Tal como refleja la tabla 4 , se trata de comunas con altas tasas de desempleo (sobre un 15\%), altas cifras de pobreza (entre un $30 \%$ y $45 \%$ ) y con ingresos mensuales que en promedio oscilan entre un $45 \%$ y un $63 \%$ de los percibidos en Concepción, muy por debajo de la media nacional. ${ }^{8}$ Se trata de una situación recesiva que muestra comunas con una preocupante carencia de áreas verdes $^{9}$ y de equipamiento comunitario, y cuyos porcentajes de ingresos munici-

8 De acuerdo con la encuesta Casen 2009, el ingreso promedio mensual por hogar en Chile (\$646.106) alcanzaba aproximadamente los USD 1.186 mensuales (al cambio del 22/09/09, $\$ 544,5$ por dólar); en Coronel llegaba a los USD 866, en Lota a USD 790, en Curanilahue a USD 745 y en Lebu a tan solo a USD 610.

9 De acuerdo con la Organización Mundial de la Salud (oms), debiese haber un mínimo de 9,2 $\mathrm{m}^{2}$ de áreas verdes por habitante. Lota, Curanilahue y Lebu ni siquiera llegan a los $2 \mathrm{~m}^{2} / \mathrm{hab}$. 
pales autónomos son extremadamente bajos (menos del 10\%): un escenario de estancamiento que nos habla de localidades con pocas actividades económicas y productivas.

La excepción a este respecto es Coronel, la comuna con el mayor porcentaje de ingresos municipales autónomos (24\%), situación que coincide con la voluntad de renovar su base económica mediante la generación de nuevos factores de retención, como la industria pesquera y la actividad portuaria. La comuna arrastra, eso sí, severos problemas de contaminación y de deterioro urbano, que se fueron acentuando con el terremoto de 2010 y la instalación de dos nuevas termoeléctricas, que se suman a la ya existente desde 1970 .

TABLA 4 Indicadores demográficos y sociales de las principales comunas mineras de la cuenca carbonífera Concepción-Arauco

\begin{tabular}{|l|c|c|c|c|c|c|}
\cline { 2 - 7 } & $\begin{array}{c}\text { DESEMPLEO } \\
\text { 2009 (\%) }\end{array}$ & $\begin{array}{c}\text { INGRESO POR } \\
\text { HOGAR 2009 } \\
\text { (CLP) }\end{array}$ & $\begin{array}{c}\text { POBREZA } \\
\text { 2OI I (\%) }\end{array}$ & $\begin{array}{c}\text { ESCOLARIDAD } \\
\text { INCOMPLETA } \\
(\%)\end{array}$ & $\begin{array}{c}\text { \% INGRESOS } \\
\text { MUNICIPALES } \\
\text { AUTÓNOMOS } \\
\text { 20I4 }\end{array}$ & $\begin{array}{c}\text { ÁREAS } \\
\text { VERDES } \\
\text { M2/HAB. } \\
\mathbf{2 0 I 4}\end{array}$ \\
\hline Coronel & 15,9 & 472.000 & 30,3 & 51,0 & 24,4 & 3,60 \\
\hline Lota & 15,5 & 430.327 & 35,6 & 54,7 & 8,6 & 1,87 \\
\hline Curanilahue & 10,4 & 405.756 & 39,1 & 65,2 & 8,7 & 1,90 \\
\hline Lebu & 18,8 & 338.554 & 45,0 & 74,1 & 9,6 & 1,50 \\
\hline Concepción & 10,9 & 747.421 & 26,1 & 41,3 & 62,6 & 4,66 \\
\hline
\end{tabular}

FUENTE ELABORACIÓN PROPIA CON DATOS DEL OBSERVATORIO URBANO DEL MINVU, ENCUESTA CASEN, Y DE LOS REPORTES ESTADÍSTICOS COMUNALES DE LA BIBLIOTECA DEL CONGRESO NACIONAL

Coincidente con lo anterior, la evolución de la población muestra un estancamiento demográfico en Lota en el año 1970. A partir de esos años, su población se estancó por debajo de los 50.000 habitantes, experimentando incluso una leve contracción. Lo interesante de este escenario es que no se trata de una anomalía que vendría a confirmar que la historia del desarrollo urbano no es lineal. Por el contrario, la evolución urbana se caracterizaría por experimentar fases de crecimiento, estancamiento y declive, producto de transformaciones y nuevas condiciones económicas, sociales y políticas (Fritsche et al., 2007), tal como sugería la literatura de las shrinking cities de mediados de los noventa.

TABLA 5 | Evolución demográfica de las comunas mineras de la cuenca carbonífera Concepción-Arauco

\begin{tabular}{|l|r|r|r|r|r|c|}
\hline & I930 & I952 & I970 & I982 & 2002 & 20I2 \\
\hline Penco & 11.189 & 22.606 & 28.245 & 33.360 & 46.016 & 54.114 \\
\hline Coronel & 20.632 & 36.280 & 58.740 & 70.371 & 95.528 & 110.657 \\
\hline Lota & 27.736 & 45.411 & 50.128 & 48.814 & 49.889 & 47.627 \\
\hline Curanilahue & 8.527 & 12.842 & 21.722 & 27.692 & 31.943 & 30.198 \\
\hline Lebu & 14.751 & 9.859 & 17.191 & 22.445 & 25.035 & 25.754 \\
\hline Cuenca $\left(^{*}\right)$ & 135.400 & 245.250 & 388.575 & 525.000 & 665.720 & 693.202 \\
\hline
\end{tabular}

$\left(^{*}\right)$ TOTAL APROXIMADO DE POBLACIÓN DE TODAS LAS COMUNAS EN LAS CUALES SE EXTIENDE LA CUENCA. FUENTE ELABORACIÓN PROPIA CON DATOS DEL INSTITUTO NACIONAL DE ESTADÍSTICAS (INE) 
En los casos de Curanilahue ${ }^{10}$ y Lebu se observan situaciones similares a partir de la década de 1980, aunque menos acentuadas, estancándose la población en torno a los 30.000 y 25.000 habitantes, respectivamente. La ausencia de incremento demográfico, e incluso un leve decrecimiento de población, es un claro indicador de importantes procesos de emigración poblacional y declive urbano. La excepción la constituye Coronel, ciudad que en el mismo lapso pasó de los 58.000 habitantes a 110.000 en la década de 2010, si bien sus indicadores sociales continúan siendo deficitarios.

Aunque tempranamente, en Lota y Coronel hubo voces que identificaron el patrimonio minero como el elemento clave para el renacimiento de la ciudad, aunque ello no derivó en una política decidida, ni se transformó en programas, iniciativas y proyectos coordinados, coherentes entre sí. Una vez experimentado el fracaso de los planes de reconversión, el potencial turístico del patrimonio minero en ruinas apareció como único horizonte posible para salir de la situación de declive (I. Municipalidad de Lota, 2014).

En este sentido, se ha señalado que la sostenibilidad de la actividad turística patrimonial en contextos otrora mineros estaría determinada por el factor de localización, sugiriéndose que "la posibilidad de impulsar un desarrollo turístico patrimonial se ve firmemente potenciada por su condición de territorio poblado" (López \& Pérez, 2013, p. 226). Sin embargo, este análisis no considera adecuadamente el peso de las criticidades socioeconómicas de algunas comunas de la cuenca, la ausencia de infraestructura turística y las deficiencias de transporte. Se olvida también que el turismo minero industrial es un tipo de turismo especializado y no masivo (Gallego, 2011), y que la actividad turística conlleva una serie riesgos, pues sus impactos positivos muchas veces no son capaces de compensar aquellos negativos (Moreira, Prevot \& Segre, 2010). Resulta improbable, entonces, que ciudades como Curanilahue, Lota o Lebu logren salir del estancamiento gracias al turismo.

Tal vez lo más llamativo radique en la dificultad de prever a nivel local un horizonte de posibilidades que exceda la actividad turística, la ausencia de lineamientos estratégicos comunes y la falta de coordinación entre las instituciones del Estado y las municipalidades. También sorprende la pasividad de las universidades regionales en este contexto, las cuales, a partir del trabajo de investigación que vienen desarrollando algunos académicos, podrían servir de nexo y articulador entre las organizaciones comunitarias y las entidades estatales en la labor de elaborar estrategias que surjan de los propios territorios, y con una visión de conjunto que conciba la cuenca Concepción-Arauco como un solo sistema territorial en términos culturales, productivos y sociales.

10 Entre 1992 y 2015 la población de Curanilahue sufrió una leve contracción (-6\%), pasando de 33.000 a 31.000 habitantes, aproximadamente. En el mismo periodo la población de Chile aumentó en un 35\%. 
TABLA 6 | Resumen, diagnóstico y principios de gestión patrimonial

\begin{tabular}{|l|l|l|}
\hline \multicolumn{1}{|c|}{ DIAGNóstico } & \multicolumn{1}{|c|}{ CONCEPCIÓN-ARAUCO } & \multicolumn{1}{c|}{$\begin{array}{c}\text { NORD-PAS DE CALAIS EN } \\
\text { FRANCIA }\end{array}$} \\
\hline Disponibilidad & Parcial & Buena \\
\hline Responsable & No, fragmentación municipal & Sí, ente suprarregional \\
\hline Conflictos socioambientales & Graves, no abordados & $\begin{array}{l}\text { Integrados al Sistema de Gestión } \\
\text { Patrimonial (sGP) }\end{array}$ \\
\hline Delimitación área patrimonial & Insuficiente & Adecuada \\
\hline $\begin{array}{l}\text { Identificación elementos } \\
\text { patrimoniales }\end{array}$ & Media & Alta \\
\hline Conservación & Baja & Alta \\
\hline Principios del sGP & Concepción-Arauco & Nord-Pas de Calais en Francia \\
\hline Englobar la diversidad & Escasa & Alta \\
\hline Claridad y coordinación & No lo considera & Interna alta, externa media \\
\hline Preparación para riesgos & No lo considera & Intermedia \\
\hline Enfoque participativo & No tiene & Tiene, mejorable \\
\hline Desarrollo sostenible & No lo considera & Considerado \\
\hline
\end{tabular}

FUENTE ELABORACIÓN PROPIA

Analizando tanto las condiciones del patrimonio como la gestión de este en la última década en Concepción-Arauco y Nord-Pas de Calais en Francia, se observan dos realidades diametralmente opuestas (tabla 6). Por un lado, el caso chileno, aún estancado en la identificación de elementos patrimoniales y en la búsqueda de mecanismos para salvaguardarlo, sin haber siquiera delineado un sistema de gestión del patrimonio. Por otro, el francés, al adoptar la decisión de concebir el patrimonio minero de la cuenca como una sola entidad y asignarle recursos humanos y materiales, no solo avanza en la preservación del patrimonio, sino también en la elaboración de una estrategia territorial coherente, frenando el proceso de declive y mejorando las condiciones del ambiente habitado.

Es aquí donde la experiencia de la cuenca Nord-Pas de Calais en Francia puede resultar útil, en el sentido de construir alternativas que sean coherentes con las capacidades intrínsecas de los territorios y sus habitantes. En este caso, el patrimonio minero aparece como el principal recurso al cual echar mano para impulsar una estrategia que surja de las expectativas y necesidades de las propias comunidades y que sea sostenible en el tiempo. Al contrastar ambas realidades, queda en evidencia que el tratamiento dado al patrimonio en el caso chileno ha sido negligente y que la ausencia de iniciativas serias de recuperación patrimonial no se explican por las diferencias económicas entre ambos países, conminándonos a hacernos cargo del patrimonio de un modo más responsable que el aplicado hasta ahora. 


\section{Conclusión}

Si las iniciativas tendientes a la preservación del patrimonio minero no parecen ser capaces de evitar su destrucción, y las vías a través de las cuales han sido enfrentados los problemas urbanos, sociales y económicos en los últimos veinticinco años no han logrado los resultados ni han atraído las inversiones esperadas, y tampoco han generado actividades, mostrándose incapaces de evitar la constante emigración de población, es perfectamente lícito plantear la existencia de un problema que excede la explicación casuística del caso particular. En términos lógicos, en vez de tratarse de una dificultad intrínseca de los territorios de la cuenca carbonífera en tanto tales, el problema podría estar distribuido en tres dimensiones:

a. En lo inadecuado de los instrumentos de planificación disponibles para responder a la complejidad de los problemas derivados de la desindustrialización, debido a una falta de coherencia entre los objetivos propuestos y los medios (humanos, financieros y técnicos) disponibles para conseguirlos.

b. En la insuficiencia de las herramientas de diagnóstico, que no logran dar cuenta plenamente de la naturaleza multidimensional de las criticidades económicas, sociales, culturales y ambientales que enfrentan dichos territorios.

c. En la incapacidad de los actores involucrados (institucionales y comunitarios), en particular de las administraciones municipales, a menudo poco preparados para enfrentar esta coyuntura.

La pregunta que surge es: ¿cómo impulsar una gestión territorial capaz de preservar, promover y valorizar las especificidades culturales, sociales e históricas de territorios recesivos y ambientalmente frágiles, que ayude a mejorar las condiciones del ambiente habitado? Si bien se trata de una pregunta abierta, en el contexto chileno constituye una invitación a imaginar nuevas formas de planificar los territorios, asumiendo la responsabilidad de poner en el centro el mejoramiento efectivo del ambiente habitado de comunidades concretas, aspecto habitualmente subordinado a otros objetivos.

Tal vez una respuesta vaya en la dirección de integrar y aprender de la práctica de las propias comunidades. Ello teniendo presente que no importa tanto definir qué tipo de iniciativas específicas se llevan a cabo, como planear la apertura de espacios participativos y vinculantes donde las comunidades imaginen su futuro y encuentren respuestas adecuadas a sus propias problemáticas. Sin la participación y compromiso de las comunidades involucradas, rara vez las iniciativas emprendidas tienen los resultados esperados o se sostienen en el tiempo.

El ejemplo francés evidencia, además, la urgente necesidad de avanzar desde una noción centrada en el objeto patrimonial individual, a uno que conciba la cuenca como sistema territorial, lo que vuelve imprescindible una gestión del patrimonio que incluya planificación a mediano plazo, ejecución de iniciativas y monitoreo de sus resultados. El desafío es avanzar hacia una gestión del territorio que considere la cuenca Concepción-Arauco no solo como una red de sitios patrimoniales ligados a la historia del carbón, sino como un territorio cultural frágil; una gestión 
que integre dimensiones identitarias, socioculturales, económicas y ambientales, y que logre articularse de modo armónico y equilibrado con un delicado sistema medioambiental que requiere ser restaurado. Para ello debe tenerse en cuenta que la fragilidad de dicho territorio no solo está dada por elementos naturales que han sido sistemáticamente maltratados, sino también por el debilitamiento o ausencia de elementos sociales y organizativos. Pues un contexto territorial cuya comunidad está mayormente organizada, informada y movilizada, es menos frágil que aquellos donde el tejido social es más débil o se ha desmembrado, y no cuenta con herramientas para enfrentar las presiones externas.

\section{Referencias bibliográficas}

Albrecht, H. (2012). What does the Industrial Revolution signify? En J. Douet (ed.), Industrial heritage re-tooled. The TICCIH guide to industrial heritage conservation (pp. 17-23). Lancaster: Carnegie / The International Committee for the Conservation of the Industrial Heritage (тіссін).

Aracena, F. (1884). La industria del cobre en las provincias de Atacama y Coquimbo. Los grandes y valiosos depósitos carboniferos de Lota y Coronel en la Provincia de Concepción. Valparaíso: Imprenta del Nuevo Mercurio. http://www.memoriachilena.cl/archivos2/ pdfs/MC0012933.pdf

Asociación de Regiones Mineras de Europa (Euracom) (2006). Reactivando las regiones mineras de Europa. Guia de buenas prácticas. Programa Recore ("Regenerating Europe's Coaldfield Regions" - Regeneración de las regiones mineras de Europa), Asociación de Comarcar Mineras (АСОм)-España. http://sig.urbanismosevilla.org/Sevilla.art/ SevLab/m002UEb_files/pdpsp.pdf

Astorquiza, O. \& Galleguillos, Ó. (1952). Cien años del carbón de Lota: 1852-1952. Santiago: Zig-Zag.

Comisión Europea (2003). Cooperación con las ciudades. La Iniciativa Comunitaria URBAN. Texto: S. Haertel \& D. Mouqué. Luxemburgo: Oficina de Publicaciones Oficiales de las Comunidades Europeas. http://ec.europa.eu/regional_policy/sources/docgener/ presenta/cities/cities_es.pdf

Danús, H. \& Vera, S. (2010). Carbón: protagonismo del pasado, presente y futuro. Santiago: RIL.

De Dinechin, P. (2001). Identidad y reconversión en las ciudades carboniferas de Lota y CoronelChile. Santiago: Fundación Cepas.

Dirección de Obras Portuarias (DOP), Ministerio de Obras Públicas (мор), Chile (2016). Alianza CORfo-Dirección de Obras Portuarias del mop busca recuperar histórico Muelle Enacar de Lota. $D O P$, Noticias. http://www.dop.cl/noticias/Paginas/DetalledeNoticias. aspx?item=413 [Recuperado 14/10/2016].

Dumont, G. \& Debrabant, V. (2010). Les trois âges de la mine dans le Nord-Pas-de-Calais. Lille: La Voix du Nord.

Euracom (2006). Véase Asociación de Regiones Mineras de Europa (2006).

Fagalde, A. (2012). El puerto de Talcahuano y sus obras de mejoramiento. Santiago: Cámara Chilena de la Construcción (cchc). 
Ferrari, M. (Director), Bulo, O. \& Pantoja, D. (Productores ejecutivos) (2003). Subterra [Película]. Chile: Nueva Imagen / Infinity Films (España)

Fritsche, M., Langner, M., Köhler, H., Ruckes, A., Schüler, D., Zakirova, B. (...) \& Meffert, P. J. (2007). Shrinking cities: A new challenge for research in Urban Ecology. En M. Langer \& W. Endlichter (eds.), Shrinking cities: Effects on urban ecology and challenges for urban development (pp. 17-34). Frankfurt: Peter Lang.

Gallego, M. (2011). Turismo industrial: el caso alemán. ROTUR/Revista de Ocio y Turismo, 4(1), 117-138. https://doi.org/10.17979/rotur.2011.4.1.1255

Garcés, E. (1999). Las ciudades del salitre. Un estudio de las oficinas salitreras en la Región de Antofagasta. Santiago: Orígenes.

Godoy, M. (2015). Las casas de la empresa: paternalismo industrial y construcción del espacio urbano en Chile. Lota 1900-1950. Universum, 30(1), 115-136. http://dx.doi. org/10.4067/S0718-23762015000100008

I. Municipalidad de Lota (2014). Actualización Plan de Desarrollo Comunal 2014-2016. Lota: I. Municipalidad de Lota. http://bit.ly/2gPnvex

López, M. \& Pérez, L. (2013). Sustentabilidad del turismo en el patrimonio minero: modelo conceptual e indicadores para el exterritorio carbonífero de Lota y Coronel. EURE, 39(118), 119-230. http://dx.doi.org/10.4067/S0250-71612013000300009

Mackay, J. (1912). Recuerdos y apuntes 1820-1890. Concepción: Murray \& Co.

Marshall, T., Rog, D., Ogunbyi, A. \& Dubsky, J. (2012). West Virginia National Coal Heritage Area Evaluation Findings. Rockville, MD: Westat. https://www.pdffiller.com/en/ project/139934990.htm?f_hash=d348a0

Mazzei de Grazia, L. (1997). Los británicos y el carbón en Chile. Atenea [Universidad de Concepción], (475), 137-167. http://www.memoriachilena.cl/archivos2/pdfs/ MC0002463.pdf

Ministerio de Hacienda, Chile. (2004). Informe de sintesis. Evaluación de impacto. Programa de reconversión laboral y productiva de la zona del carbón. Corporación de Fomento (Corfo). Santiago: Ministerio de Hacienda. http://repositoriodigital.corfo.cl/bitstream/ handle/11373/1352/Informe\%20de\%20Sintesis.pdf?sequence $=2$

Ministerio de Vivienda y Urbanismo (Minvu), Chile. (2010). Plan de Regeneración Urbana. Comuna de Lota, Provincia de Concepción, Región del Biobio. Santiago: Dirección de Desarrollo Urbano, Minvu. http://bit.ly/2xPneTe

Miranda, R. (1926). Monografía geográfica é histórica de la comuna de Tomé. Concepción: Westcott \& Co. http://www.memoriachilena.cl/archivos2/pdfs/MC0027800.pdf

Mission Bassin Minier. (2012). Bassin Minier du Nord - Pas-de-Calais en Francia. Patrimoine mondial de l'UNESCO. Oignies: Mission Bassin Minier. http://bit.ly/2yxr4iL

Moreira Filho, M., Prevot Nascimento, R. \& Segre, L. M. (2010). ¿Cúal es el papel del turismo en el desarrollo local? Un análisis crítico del cluster turístico de Santa Teresa - RJ, Brasil. Estudios y Perspectivas en Turismo, 19(5), 812-834. http://www.redalyc.org/ articulo.oa?id $=180717609013$

Ortega, L. (1988). La industria del carbón en Chile entre 1840 y 1880. Santiago: Cuadernos de Humanidades 1, Universidad de Santiago de Chile (Usach).

Ortiz Letelier, F. (1985). El movimiento obrero en Chile, 1891-1919. Madrid: Michay. http:// www.blest.eu/biblio/ortiz/index.html 
Pérez, L. \& Sanhueza, F. (2015). Curanilahue: huellas del habitar desplegado por la minería del carbón. En M. López \& L. Pérez (eds.), Parques mineros, economuseos y geoparques. Estrategias de puestas en valor (pp. 12-27). Concepción: Stoq.

Pérez, L. \& Valenzuela, C. (2010). Lebu: minería del carbón y evolución urbana desde 1862 a la actualidad. Urbano, 13(21), 5-19. http://revistas.ubiobio.cl/index.php/RU/article/ view/312

Pérez, L., Muñoz, M. D. \& Sanhueza, R. (2004) El patrimonio industrial en la estimulación del desarrollo: intervenciones y revitalización en Lota Alto (1997-2000). Urbano, 7(10), 9-18. http://www.redalyc.org/articulo.oa?id=19871003

Pérez, R. \& Fernández, V. (2015). Los paisajes culturales de Unesco desde la perspectiva de América Latina y el Caribe. Conceptualizaciones, situaciones y potencialidades. INVI, 85(30), pp. 181-214. http://dx.doi.org/10.4067/S0718-83582015000300006

Reicher, C. (2008). International Building Exhibition Emscher Park: The projects 10 years later. Essen: Klartext.

Rink, D., Haase, A., Bernt, M., Arndt, T. \& Ludwig, J. (2010). Urban shrinkage in Leipzig and Halle, the Leipzig-Halle urban region, Germany. Leipzig: Helmholtz Centre for Environmental Research (UFz). https://www.ufz.de/export/data/400/39014_WP2_ report_Leipzig_Halle_kompr.pdf

Ríos, J. (2011). Monumentos Nacionales: Octava Región del Biobio. Santiago: Universitaria.

Rodríguez, J. \& Medina, P. (2011). Reconversión, daño y abandono en la ciudad de Lota. Atenea, (504), 147-176. http://dx.doi.org/10.4067/S0718-04622011000200009

Rolos, G. (2008). L'habitat minier en Region Nord-Pas-de-Calais. Histoire et évolution 1825-1970.

Tome I. Oignies: Mission Bassin Minier Nord-Pas de Calais. http://bit.ly/2kWiVPS

Santa Cruz, J. (2014). Taranto "refrattaria allo sviluppo". Come si raccontano la crisi e il declino urbano. Etnografia e Ricerca Qualitativa, 2 (2014), 287-299.

Shifflett, C. (2000). Coal Towns: Life, work, and culture in company towns of Southern Appalachia, 1880-1960. Knoxville, tn: University of Tennessee Press.

Smith, P. (2012). Choosing what to preserve. En J. Douet (ed.), Industrial heritage re-tooled. The TICCIH guide to industrial heritage conservation (pp. 86-93). Lancaster: Carnegie / The International Committee for the Conservation of the Industrial Heritage (тіссін).

Torres, C. (2013). Los riesgos por el "abandono cultural" del patrimonio industrial: maestranzas ferroviarias en Chile. Apuntes, 26(2), 52-67. http://dx.doi.org/10.11144/Javeriana. APC26-2.rabp

Unesco (Organización de las Naciones Unidas para la Educación, la Ciencia y la Cultura). (2011). Blaenavon World Heritage. Site Management Plan 2011-2016. http://bit. ly/1VNFuOE

Unesco (Organización de las Naciones Unidas para la Educación, la Ciencia y la Cultura). (2013). Operational guidelines for the implementation of the world heritage convention. [En línea]. World Heritage Centre. http://whc.unesco.org/archive/opguide13-en.pdf

Unesco (Organización de las Naciones Unidas para la Educación, la Ciencia y la Cultura). (2014). Gestión del Patrimonio Mundial Cultural: Manual de referencia. París: Centro del Patrimonio Mundial de la Unesco / Centro Internacional de Estudios para la Conservación y la Restauración de los Bienes Culturales (Iccrom) / Consejo Internacional de Monumentos y Sitios (Icomos) / Unión Internacional para la Conservación de la Naturaleza (UICN). https://ilamdocs.org/documento/3335/ 